\title{
Learning by Doing: Learning to Implement the TEI Guidelines Through Digital Classics Publication
}

\author{
Stella Dee*, Maryam Foradi ${ }^{\dagger}$ and Filip Šarić ${ }^{\dagger}$ \\ *Tufts University, \\ ${ }^{\dagger}$ University of Leipzig
}

\begin{abstract}
This chapter reviews the current online resources available to learn the TEI Guidelines for structured data in the humanities, as well as the theory that drives their construction and continued improvement. It focuses on the EpiDoc community as a positive example of a specialist community of practitioners who take a flexible approach to TEI instruction that meets both the shared and individual needs of scholars (cf. Bodard and Stoyanova, q.v.). We also address some of the barriers to multilingual contribution to the online digital Classics, and report on a case study in which we discuss the experience of Masters-level students trained in non-digital Classics methods with the translation and transcription of texts via the Perseids platform (cf. Almas and Beaulieu, q.v.). We consider how templates revealing the TEI markup allow students to gain comfort and familiarity with the XML, as well as to enable their own work to serve as a model for future contributors. However, we also note the pedagogical limitations of contribution without direct instruction as seen in this case study, and posit that a mixed model of experiential education combined with interpersonal guidance might better serve students hoping to contribute machine-actionable data in the digital Classics.
\end{abstract}

\section{How to cite this book chapter:}

Dee, S, Foradi, M and Šarić, F. 2016. Learning By Doing: Learning to Implement the TEI Guidelines Through Digital Classics Publication. In: Bodard, G \& Romanello, M (eds.) Digital Classics Outside the Echo-Chamber: Teaching, Knowledge Exchange \& Public Engagement, Pp. 15-32. London: Ubiquity Press. DOI: http://dx.doi. org/10.5334/bat.b. License: CC-BY 4.0. 


\section{Introduction}

Increasingly, texts that manage to find a readership 'outside the echo chamber' do so through open publication online, often as part of a larger repository, digital library, or website. Of those texts that originate from scholarly sources, many are encoded according to the Text Encoding Initiative (TEI) standards for XML markup. ${ }^{1}$ The TEI standards and consortium provide guidelines for the machine-actionable markup of texts in the humanities, including the Classics. Since 1994, familiarity and comfort with TEI XML has often been a prerequisite for an ability to navigate, judge, and participate in the various aspects of open-access digital humanities research. However, to those students and researchers with little prior exposure to the data structures that underpin computational work, TEI XML, or even the concept of a markup language, is not self-explanatory.

This chapter will examine the theory and practice of how those with some form of prior academic expertise in the humanities, more specifically in the ancient Greek and Latin languages and literature, can begin to learn to encode TEI XML text in an online environment. We briefly review some of the theory behind online and adult learning, as well as some of the prior resources available to those hoping to learn to encode texts in TEI XML. We also address some of the communities of practice, including EpiDoc, a curated subset of the TEI Guidelines designed for epigraphic markup, and the papyrologists. These communities of practice have successfully taught each other the skills needed to make digital contributions, with this instruction often happening in a digital space. For all resources under discussion, we reflect on parallels between various practices in the history of education and the principles underlying the technical development of the resources.

Above all, we hope to demonstrate that unfamiliarity with TEI XML need not preclude beginning to make real contributions to the scholarship of cultural antiquity. In fact, we will describe the experience of a number of students and researchers with no formal education in the digital humanities as they began contributing new TEI EpiDoc encoded translations of Classical texts through the Perseids platform, an online resource for the collaborative creation and editing of text in the Classics. ${ }^{2}$ In the process, these students became more comfortable working in an elementary way with academic markup. While Almas and Beaulieu (q.v.) discuss in detail the way in which use of the Perseids platform changes interpersonal dynamics and learning within a classroom setting, we concentrate here on how the Perseids platform facilitates self-directed, remotely-collaborative and digital learning.

We also review the challenges facing the markup of Classics material that is truly multilingual. This is because the greatest barrier we ourselves have witnessed to contribution and participation in the digital classics is not the difficulties posed by understanding the technologies themselves, but rather the 
difficulties posed by the linguistic limitations of those technologies. While a full discussion of multilingual interfaces in the digital Classics is outside the scope of this chapter, we will touch on some of the technical linguistic barriers most frequently encountered by our project.

To date, the Perseids platform has supported scholars and students working with TEI EpiDoc in a number of languages, including Italian, French, Georgian, English, Latin, Ancient Greek, Persian, Arabic, and Hebrew. Of these languages, the most significant technical barriers to learning digital methodologies for working with Classical texts exist for those users whose preferred spoken language is Persian, Arabic, or Hebrew, most particularly those who work with conjoined scripts such as Persian or Arabic. ${ }^{3}$ As a consequence, we will focus our user experience section on the issues encountered while working with textual markup and right-to-left script, in particular those of one of the authors, who has been writing and marking-up an original Persian translation of Thucydides' History of the Peloponnesian War. We believe that improving the technical infrastructure for working with multilingual TEI XML is critical to opening up teaching, knowledge exchange, and public engagement in the digital Classics.

\section{Learning to Read, Learning to Edit, Learning Markup}

We focus our attention here on a learner audience at the undergraduate level or above, who are studying or have studied subjects within the humanities, particularly Classics. For this audience, textual markup can be a new means of communicating knowledge that they already possess. Since nearly all students and scholars of the humanities require skills of textual criticism, and textual markup can be understood as a means of encoding textual criticism and interpretation, basic structural and critical markup can be relatively easier for these learners to comprehend. However, Peter Shillingsburg points out that markup can do many things which are not part of a traditional Western education in the humanities; 'scholarly editors are first and foremost textual critics. They are also bibliographers and they know how to conduct literary and historical research. But they are usually not also librarians, typesetters, printers, publishers, book designers, programmers, web-masters, or systems analysts." One advantage of the TEI is that it can serve as a channel of communication between one area of expertise-that of textual criticism, including familiarity with the material, philological, and bibliographic record-into another, that of production and representation. It allows the publisher, designers and programmers to extract the information they need, and for scholars to retain the analytical record in post-production. The tendency of those projects adhering to the TEI to be collaborative in nature is no less true of the TEI itself, which suggests a community of practice in its very name. 
How much of this workflow students of the TEI, or aspiring digital Classicists need to master is an open question, the answer to which varies by individual. However, a significant proportion of learners hope to be directly involved in the publication and visual interface of their markup. A respondent to a recent survey on Learning the TEI requested '...instruction on file publication, rather than only TEI encoding. It is easier to learn the TEI in a self-taught manner using the Guidelines than it is to learn the workflow around TEI, from encoding and transforming and visualizing to publishing in a self-taught way, because that involves a lot more technologies and tools. ${ }^{5}$ Of the various learning resources for the TEI mentioned below, different resources enable exposure to different stages of this workflow, and include different degrees of collaboration with both humans and machines. Of the resources mentioned in this paper, we find the community of papyrologists and the Perseids community to have achieved particular success in involving their users in the publication of their own material. In fact, Perseids and the papyrology environment effectively minimize the need for users to deeply understand markup at all, serving the call of another survey respondent, who declared that 'it's time to make the TEI actually useful to individual Humanists with no digital background, and no support from DH centres.' Through these platforms, students and scholars can create meaningful markup without deep familiarity with the TEI. In effect, learning to read and learning to edit can be enough to begin marking-up. Yet there will always be students who want to learn to make more full use of the technologies upon which these platforms rely; therefore, the next sections will examine the theory behind digital learning, as well as some of the resources currently in place for learning the TEI in a digital environment.

\section{Digital Pedagogy}

Most students who learn both the theory and practice of the academic Classics and the academic digital humanities currently do so primarily in a physical classroom. ${ }^{7}$ However, digital tools and resources often serve as a supplement, and, for a significant minority, a replacement for classroom education. This has sparked a growing field of digital pedagogy-teachers, researchers, and students experimenting with effective strategies for online learning. The next section will provide an illustrative selection of relevant literature from the perspective of the digital Classics, with the intention of defining relevant terms for the resource reviews and case study later in the chapter.

\subsection{Growth out of Prior Pedagogical Thought}

A brief review of some terminology commonly used in Anglo-American academic discourse on pedagogy serves as a useful introduction to the discussion of resources later in the chapter. Frontal teaching, also known as 'chalk-and-talk' or teacher-centered instruction, refers to the practice in which a teacher stands 
in front of a class, often with a textbook, doing most of the talking in an effort to impart knowledge to the student. By contrast, in the various forms of studentcentered instruction, "knowledge is "discovered" by the learner.' We consider constructivist, problem-based, and experiential learning to all be forms of studentcentered instruction - in other words, learning by doing. Kirschner, Sweller and Clark describe the common elements of these different methodologies: 'first they challenge students to solve "authentic" problems or acquire complex knowledge in information-rich settings based on the assumption that having learners construct their own solutions leads to the most effective learning experience. Second, they appear to assume that knowledge can best be acquired through experience based on the procedures of the discipline.' They go on to critique these forms of instruction, which they describe as using 'minimal guidance.' Part of their criticism is the idea that a student scientist will never draw the same conclusions from an experiment as a professional scientist, and can be led astray by those that they do draw. While some of the resources described here take a student centered, minimally-guided approach, we suggest that they do not fall into this trap, since those resources cater primarily to scholars who are learning mostly new techniques, rather than new concepts - the idea that one can enclose a paragraph in a $<\mathrm{p}\rangle$, as opposed to idea that one can separate text into paragraphs at all.

Classroom teaching can be described as discursive, adaptive, interactive, collaborative, and reflective. ${ }^{10}$ A classroom teacher draws out discussion, a form of discursivity. They adapt their syllabus according to the needs of a particular student or group. They ask their students to reflect, giving critical feedback on an activity or concept. They ask their students to think together, collaboratively, enabling students to learn from one another, but respond with individual answers. They interact with the source text, in the form of a book or manuscript, writing their own translations or commentaries.

In a purely digital environment, the same activities and ways of going about things are reinvented. The environment itself can be designed to foster productive dialogue online, either in real time or not; the interface can be designed to adapt to the needs of a particular user, whether that means enlarging the type for someone with a visual impairment, or flipping the placement of elements on an HTML page for someone who reads in a right-to-left script. Dynamic exercises interact with the user, and the ability of the learner to communicate their feedback to the designer encourages reflection on the success of the environment for learning. We will return to these parallels between traditional and digital instruction in a few pages, when we begin to review some of the resources available for learning markup.

\subsection{Adult Learning}

Since most of the currently-available resources that introduce Classicists to digital methods and markup are targeted at adults, it seems appropriate to briefly review some of the theoretical tenets of adult education. In this chapter, we define 'adults' 
as those no longer in obligatory education, whatever the degree of obligatory education in their context may be. This definition considers university students to be adults, as well as professional scholars and researchers. Research suggests that for this cohort, task-based, also called use-directed, curricular organization is critical. ${ }^{11}$ In other words, because adults operate under logistical pressures that are often absent from the lives of children, they expect the process of learning to be as compelling and worthwhile as the product. ${ }^{12} \mathrm{~A}$ Classicist learning TEI markup might reasonably expect that they can further their work while still learning the best ways and technical arguments to encode their text. 'The approach to adult education will be via the route of situations, not subjects. ${ }^{13}$

Online resources for Classicists learning to encode in XML must therefore seek to anticipate those situations in which a Classicist unfamiliar with the digital humanities might turn to XML encoding-whether as a way to work collaboratively with far-flung colleagues, to create a digital edition that sparks the imagination of members in their local community, or to build dynamic exercises to help their students learn a language. Moreover, these resources must support an approach that is self-directed, ${ }^{14}$ although not necessarily minimally guided. While in the classroom 'one cannot equally serve both objectives-the generalist as well as the specialist-in [a short time], ${ }^{15}$ a digital learning environment can, and usually should, provide resources for both. Perhaps one of the most important points with respect to the final section of this chapter, which discusses the Perseids platform, is that people can learn without necessarily being taught. ${ }^{16}$

\subsection{Digital Pedagogy}

Much of the recent thought in digital pedagogy discusses how best to take advantage of the increased student autonomy and flexibility granted by the digital environment, as well as how best to cope with the accompanying distraction and possible lack of rigor. Through 'transferring to students the responsibility for accessing, sequencing and deriving meaning from information, hypertext was seen to provide an environment in which discovery learning might flourish. ${ }^{17}$ Moreover, the collaborative yet geographically unbound nature of the digital environment allows expertise to be shared across boundaries of geography and language, ${ }^{18}$ although there are technical barriers to this exchange that we will confront in later sections. This enables early, graduated, and supervised participation in the creation of content, provided that designers 'redesign the learning environment so that newcomers can legitimately and peripherally participate in authentic social practice in rich and productive ways, in short, make it possible for learners to 'steal' the knowledge they need. ${ }^{19}$ The flexibility of the digital environment benefits learners by providing resources that are accessible on the learner's own time and that suit the learner's existing familiarities and motivation. ${ }^{20}$ Ruell, however, draws on data from the online instruction offered by Harvard University to caution that resources for digital learning must impose external time limits and routine assessment to ensure student progress in the face of constant distraction, 
the downside of the increased flexibility. ${ }^{21}$ Scardamalia and Bereiter discuss the need for resources grounded in pedagogical thought; they call for 'intentional learning environments' that are able to identify 'knowledge lacks', or student areas of unfamiliarity, as well as to make use of 'multiple pass strategies', that ask learners not simply to repeat, but to reflectively re-interpret. ${ }^{22}$

Chickering and Ehrmann formulated seven 'good practice' elements in online instruction. We list them here, in the hope that they might serve as initial guide for evaluating resources discussed later. According to these criteria, a pedagogically sound online instructional resource: ${ }^{23}$

1. encourages contact between students and faculty

2. develops reciprocity and cooperation among students

3. encourages active learning

4. gives prompt feedback

5. emphasizes time on task

6. communicates high expectations

7. respects diverse talents and ways of learning.

We would recommend appending at least two more to the original seven:

8. acknowledges and makes every contextually reasonable attempt to accommodate the multilingualism of a global digital space

9. enables learners to contribute as soon and as helpfully as possible to research in the field.

This theory is the lens through which we view and evaluate the resources discussed below. Although terms may shift in meaning or even become metaphors when applied to digital resources-students become 'learners' or 'users', unresponsive or static lists of facts can be a form of 'frontal instruction'-we find this thinking useful as we evaluate the digital landscape.

The following sections will examine the development of various online resources for learning TEI markup, moving from those that are more static, or frontal, to those that are more collaborative and responsive. We will focus on the EpiDoc and papyrology communities for their particular success in teaching digital humanities methodology in an online environment. Finally, we will address the role of the Perseids project as a platform for collaborative editing that has grown out of these communities, including EpiDoc, the Perseus Digital Library, and the Alpheios Project; in particular, we will recount our experience using the Perseids platform to teach markup 'by doing.'

\section{Teaching Resources}

The following sites are all explicitly designed for users hoping to learn the TEI online. Unlike the collaborative platforms for editing described later, these sites 
have the benefit of being open to anyone with the necessary internet connection and linguistic abilities. They are scalable, in that questions or problems do not need to wait on a human being to answer them, largely because there is no opportunity to ask questions or voice problems. The webpages published by universities, as well as the resources published by particular individuals, often share a presentation-oriented approach. They provide information, leaving the user to figure out how best to make use of it. TEI By Example is a notable exception, in that it is a site designed explicitly for those hoping to learn the TEI as self-guided individuals, and contains tests, exercises, and pedagogical sequencing. However, TEI By Example cannot be considered an example of 'learning by doing' as we intend it, since the user of TEI By Example is not necessarily working on something personally productive for the user or scholar.

\subsection{University Resource Sites and Individual Initiatives}

Several universities host sites with basic resources for learning the TEI. The majority of these sites curate or list materials used in the classroom. As a consequence, while these sites certainly do work towards making markup accessible outside the echo chamber, they typically do not serve as examples of enacted digital pedagogy. Rather, their style of curating resources makes them the digital analogue to an extremely teacher-centered approach to classroom instruction. Two particularly rich examples of these sites are those run by Oxford University and Brown University. Just as a teacher lectures, so do these sites provide resources, sometimes sequentially, without making the process necessarily interactive, reflective, collaborative or user-driven. Similarly, a number of introductions to the TEI created by individuals affiliated with the TEI community serve as an example of frontal instruction in a digital space. While incredibly helpful and necessary for a raw beginner, they cannot be said to actively involve learners in the 'doing' of the TEI.

The TEI@Oxford Teaching page publishes a list of links to PDFs, XML, and other material from TEI@Oxford presentations, including many with topics of interest to aspiring digital classicists, such as 'A Very Intensive Introduction to TEI with Manuscript Description, 'TEI:pas pour les nuls,' and 'Getting to know TEI P5: Everything you wanted to know about TEI P5 (but were afraid to ask)!' ${ }^{24}$ Many of these links provide detailed and topical information of enormous use to an independently motivated reader who knows what they are looking for. However, they are not sequenced, searchable, nor explanatory at the most fundamental level, and consequently are most likely unable to meet the needs of a true novice. The TEI Consortium Experimental Getting Started Guide, also hosted by Oxford, is similarly static. Perhaps the most helpful aspect of the Guide is a clear and extensive explanation of when, why and how to use the TEI. 
The Women Writers Project (WWP) at Brown University, in addition to hosting face-to-face seminars and workshops to teach text encoding, publishes a number of resources for learning to use TEI markup..$^{25}$ Resources for Teaching and Learning Text Encoding curates slides, lecture notes, and other materials developed by the WWP for internal workshops. Most modules published on the site include a source, notes, and slides, although a set of basic templates with a schema and stylesheet are also available, as part of a simple package for the presentation of encoded files. The majority of the material published as Resources for Teaching and Learning Text Encoding is simply lecture material generously shared online by professors, but nevertheless divorced from the lecture in which it was presented. Therefore, this area is most likely more useful for teachers seeking classroom resources than students seeking instruction. The Guide to Scholarly Editing stands alone as an excellent introduction to project workflow, scholarly encoding, and the TEI more specifically. However, the digital textbook lacks the examples, tutorials, and community interaction that some learners find useful. The Training Materials include reading, tutorials, how-tos, and references. While the most comprehensive of the WWP resources from a pedagogical standpoint, they also seem to be curated for the primary purpose of supporting in-house instruction and not online drop-ins.

The three individual initiatives described below are all authored by people belonging to the wider TEI community. The Slideshare PowerPoint developed by Laura Mandell is titled 'Introduction to Digital Textual Editing: An UNOFFICIAL Guide to the Value of TEI.26 Covering TEI as well as XSLT, Mandell's presentation is coupled with a twenty-minute lecture, and provides a convincing explanation of and justification for the use of both TEI and XSLT. Also accessible from a large, well-known commercial database is the instructional YouTube video titled 'TEI: an overview' published by Amanda Chesley, a current graduate student in the digital humanities. ${ }^{27}$ Slightly less accessible to a non-academic community, but perhaps more useful for classicists who are already familiar with the basic concepts of textual markup, are the domainspecific 'Cheatsheets' assembled by Marjorie Burghart. These sheets answer encoding questions that re-occur frequently in various sub-disciplines, and are published on Burghart's personal site as well as the TEI Wiki. Helpful and easy to re-use, these sheets are an excellent resource for any classicist who needs quick answers to questions that arise during their process of encoding. ${ }^{28}$

We hope to be clear that applying the descriptor 'teacher centered' to the resources above is by no means meant to be a value judgment. In particular, the resources developed by individual scholars include some of the most concise, clear, and accessible resources encouraging scholars within the humanities to overcome a lack of technical comfort in order to make use of the TEI. These multimedia resources make an active case for use of the TEI through arguments that assume no prior knowledge of textual encoding. Although the direct impact has not been assessed, these resources are likely to go a long way 
towards breaking out of the markup community that can sometimes be an echo chamber. However, other resources are required for those beginners who then hope to begin participating directly in encoding work.

\subsection{Inter-institutional Resources}

With an increased scholarly focus on pedagogy in the digital humanities, as well as rising interest from scholars outside the field, came a number of interinstitutional resources designed to provide a more guided learning experience to advanced students and academics hoping to learn the TEI. These tutorials are often more interactive than the resource directories mentioned above, but users are still in an artificial environment, marking up examples that are often from outside their area of expertise. Therefore, while some of these resources, particularly TEI By Example, could be called 'learning by doing,' there is a distinct difference between the kind of 'doing' for TEI By Example and the kind of 'doing' required by participation in the EpiDoc or Perseids community.

Teach Yourself TEI is run by the TEI Consortium and serves as a catalogue for tutorial materials concerning the TEI. ${ }^{29}$ Divided into 'Generic tutorials,' 'Guides to Local Practice,' and 'Materials from Workshops and Presentations,' the site states no ambition to be a comprehensive survey of available resources, but does provide a brief description of each listed tutorial. Also run by the TEI Consortium, the TEI Wiki is a publicly available forum for the TEI community. Although not explicitly pedagogical, it does provide an area for discussion, sample files, and various how-tos that users claim to be quite useful. ${ }^{30}$

TEI By Example is one of the first formal initiatives designed to meet the need for online support for learners of TEI XML. A collaborative work between a number of institutions, including King's College London, University College London, and the Royal Academy of Dutch Language and Literature, TEI By Example is a collection of tutorials written for novices as well as more experienced users. ${ }^{31}$ The creators of TEI By Example differ slightly in their description of the target user base. Melissa Terras wrote in a personal blog-post that 'what I needed, really, was some point and click tutorials that I could direct my masters students to after an introductory lecture on TEI ... Where were examples of marked-up texts people could see to learn from? ${ }^{32}$ We re-visit this question of Terras' in the next section, when we discuss the communities that learn markup while contributing to repositories of marked-up texts. Edward Vanhoutte describes the target audience as primarily self-directed learners, although acknowledges their possible utility for classrooms teachers, saying, 'The tutorials are designed for self-directed learning but can also be used by TEI instructors in classroom and workshop situations."' 33 The TEI By Example tutorials demonstrate the encoding of different kinds of document by style or genre, including poetry, drama, and prose. Of all the resources discussed up to 
this point, TEI By Example comes closest to being a standalone pedagogicallysensitive resource for learning the TEI.

\section{Communities of Practice}

Other models raise the questions: who even needs to learn markup? And how much comfort with markup is necessary in order to do meaningful digital work, and for whom? Two communities discussed below, the community of papyrologists and the Perseids community, provide their users with graduated exposure to XML markup, specifically markup compliant with the EpiDoc subset of the TEI Guidelines.

That tools for digital scholarly editing could serve as a pedagogical tool for learning markup may not be obvious. However, in the words of Siemens and Tittenberger, 'content is generally viewed as something that learners need to cognitively consume in order to learn. But learning is like opening a door, not filling a container. Content can be created through the process of learning, not only in advance of learning. ${ }^{34}$ While the idea of student learning through research contribution has become standard practice in the sciences, it has yet to become standard in most introductory Classics classrooms. ${ }^{35}$ The tools available to papyrologists and the Perseids platform gently introduce students and scholars of the Classics to the markup techniques of the Digital Classics, even as these students and scholars continue to conduct the kinds of scholarly annotation with which they may be more familiar.

This approach to learning markup is not nearly as inclusive nor scalable as the frontal resources described above. As of fall 2014, these resources rely on human beings, accessible via email, to answer questions. In this way, while the resources may be minimally human guided, they are still guided, to the benefit of their users. However, this lack of scalability leads to the risk of creating ever more new echo chambers instead of communities, unless concerted effort is made to keep communities in conversation, contributing to a world republic of digital humanities. ${ }^{36}$ Moreover, learners require pre-existing expertise in domain-specific methodology. While this requirement allows these resources to avoid the problems caused by 'the improper use of inquiry as a paradigm on which to base instructional strategy, ${ }^{37}$ since users are already proficient in their domain and are likely to choose appropriately among methods of inquiry, it also limits the audience that these resources are able to serve.

Both the papyrologists and the Perseids project rely upon the EpiDoc standards for the TEI guidelines. EpiDoc was originally developed for use encoding epigraphy, and like the TEI itself, EpiDoc is a community, as well as a set of guidelines. Gabriel Bodard, one of the lead authors of the EpiDoc guidelines, is very clear about this joint mission; 'it is a central goal of the EpiDoc Collaborative to create freely available tools, well-documented advice, and a lively community of training and assistance for EpiDoc projects. ${ }^{38}$ While this includes 
in-person training, like the TEI Community, EpiDoc also publishes online learning materials designed to help scholars through the process of beginning to encode their materials, including those involved in the projects below. ${ }^{39}$

\subsection{The Papyrologists}

The papyrological community shares a community-based approach to teaching digital methods. Roger Bagnall, a core member of this community, explains that 'Joshua D. Sosin, Duke University, who is the principal project leader, [sees] this nexus of papyrological resources as ceasing to be "projects" and turning instead into a community ... the central feature of the second phase of IDP is the creation of an online editing system that will allow entry of texts ... by any authorized participant. ${ }^{30}$ Gregory Crane, editor-in-chief of the Perseus Digital Library, points out that this is facilitated by a Papyrological Editor which is able to 'shield the raw TEI XML from editors, allowing them to encode very complex textual data in a more traditional format as they publish new and revise existing editions. ${ }^{41}$ In other words, the papyrological community is able to teach digital methods, with XML encoded data, without require the user to fully understand EpiDoc-compliant TEI XML.

\subsection{Perseids}

The Perseids platform also provides a space for students and scholars to gain comfort working with TEI EpiDoc markup through the process of digital scholarly editing. The Perseids platform grew out of the Perseus Digital Library and Alpheios Project; continued collaboration with these projects, as well as the Open Philology Project, provide Perseids with connections to massive repositories of openly-available scholarly text, as well as a critical focus on pedagogy (cf. Almas and Beaulieu, q.v.). All editions and translations accessible and creatable through the Perseids platform must be encoded in CTS-compliant TEI EpiDoc, creating ever more communities and guidelines which the humanities student must familiarize themselves with. ${ }^{42}$ However, Perseids provides a gentle introduction to TEI XML by allowing scholars to complete linguistic annotations without necessarily seeing the underlying XML, to write translations into pre-prepared TEI XML templates, and by providing feedback when XML is invalid.

Both Perseids and the Papyrology Editor integrate publication, or doing, into the process of learning TEI XML. A number of ongoing projects appear to be heading in a similar direction, either by supporting collaborative editing, or by lowering the barrier to publication of TEI files, or both. These include TAPAS, for publication, TEICHI, for display and download, CWRC-Writer, for inbrowser collaborative editing and standoff markup in a 'close-to-WYSIWYG' environment, and TEI Boilerplate, for easier display of TEI texts. ${ }^{43}$ 


\section{Case Studies: Benefits and Challenges of Learning Markup through Community-based Digital Scholarly Editing}

The next pages focus on user experience with the Perseids platform, particularly the lessons this experience holds for learning markup in a digital environment through participation in communities of practice. We rely on specific case studies of Masters-level Classics students who 'learned by doing, who without prior knowledge of digital methods or classroom instruction were able to work with Perseids and TEI/EpiDoc-compliant XML markup. We also address the issue of localization and multilingualism in online pedagogical resources, including Perseids, by discussing the experience of a professional translator and research scholar of translation studies working to create a TEI EpiDoc-encoded Farsi translation, direct from ancient Greek, of a section of Thucydides History of the Peloponnesian War. This will include a summary of some of the technical challenges posed by working in the digital Classics with right-to-left scripts.

\subsection{Beginning to Work with TEI Markup through Scholarly Editing}

In the spring of 2014, the Open Philology Project at the University of Leipzig Department of Digital Humanities hosted four postgraduate-level students of classics, two specialists in ancient Greek and two in Latin, all of whom had attended university in Zagreb, Croatia. None had prior experience working with digital resources. All began working with the Alpheios treebank and alignment editors for completing annotations, as accessible through the Perseids platform, which also allows for the storage and later editing of these annotations.

While the students received brief instruction on how to use the Perseids platform and Alpheios editors, they were given little to no direct instruction on TEI XML. During their time in Leipzig, they completed a number of original translations of Ancient Greek and Latin text into English. Although a research assistant conducted the initial markup of their translations for upload to Perseids, the students were responsible for completing minor XML edits afterwards. They proved themselves able to complete such edits as adding the appropriate EpiDoc markup for co-translators, splitting and renumbering words to mark Latin enclitics, and renumbering sentences in translation alignment XML.

At the end of their stay, however, the students did not feel as if they understood XML at a theoretical or practical level, despite the fact that they were able to recognize and work with it at an elementary level. This does support the limits of 'learning by doing'; ultimately, they would have required direct instruction beyond the guidance built in to the software and the occasional questions they asked to be able to independently work with TEI XML in the future. 


\subsection{Technical Barriers to Learning TEI Markup through Scholarly Editing}

Perseids has also taken steps to move outside the echo chamber of Euro-American academia, by actively engaging participation from scholars working with ancient Greek and Latin texts and translations in Georgian, Farsi, Arabic and Hebrew. However, this effort confronts a number of technical issues with effectively working with TEI markup in certain scripts. We believe these issues bear repeating here, as they serve as a very real barrier to entry to the Digital Classics and TEI EpiDoc encoding for scholars working in right-to-left (RTL) scripts.

The problems that arise include technical difficulties with both digital editing and digital publication. Most of the text editors most commonly used by scholars in the digital humanities have either no or inadequate support for RTL text. Some editors, such as Sublime, display RTL text as LTR, while others, such as Notepad++, display words correctly but shift them unpredictably while the user is working. ${ }^{44}$ Oxygen, perhaps the most commonly used editor for working with LTR TEI XML in the digital humanities, poses similar problems. While scholars working with RTL text have come up with work-arounds for nearly all of these issues, the work-arounds tend to be time consuming, frustrating and imperfect, particularly with such situations as the placement of punctuation.

As mentioned above, students are more highly motivated to learn TEI XML when they can see a visible display of their encoding, particularly in the browser. However, the browser poses no fewer challenges for those working RTL text. Meeting this challenge requires commitment on the part of the front-end developer, author of the stylesheet, or teaching materials for XSLT to understanding directionality, mirroring, and the relevant unicode encoding for RTL numbers.

Of course, supporting multilingual participation in the TEI, EpiDoc, and Perseids communities neither begins nor ends with technical support for RTL text. By choosing to write from experience, we have left out addressing issues of internationalization, localization, and vertical scripts, to name just a few. However, we believe that facing these issues is critical to the future not only of humanities markup, but humanities scholarship and its students.

\section{Lessons Learned}

Emerging evidence suggests that the most efficient path to becoming adept with academic XML markup in the digital Classics requires a combination of online resources and interpersonal support. This support can take the form of message boards, the frontal resources mentioned in this paper, or mailing lists; a recent survey found that of respondents who asked a question via the TEI mailing list, $81 \%$ received a satisfactory answer, and of those who reached out to a member of the TEI community for mentorship or guidance, $93 \%$ had 
found their contact information via the mailing list. ${ }^{45}$ Mailing lists serve the additional purpose of crowd sourcing the support, so that one teacher is never expected to be the sole resource. However, we do believe that the future will see more platforms of the kind represented by Perseids and the Papyrological Editor. These platforms foster a positive feedback loop, in which scholars learn TEI XML through following examples set by eithers, even as they create examples for those who will follow them. The major challenge lies in making this model scalable, linguistically inclusive, and meaningful across the different fields of the humanities; until it is, each community will continue to be something of an echo chamber.

\section{Notes}

1 TEI: Text Encoding Initiative: <http://www.tei-c.org/index.xml> (last accessed October 2015).

2 Perseids Project: <http://sosol.perseids.org/> (last accessed October 2015).

${ }^{3}$ Romanov, pers. Comm.

${ }^{4}$ Quoted in Rehbein \& Fritze, 2012: 48.

${ }^{5}$ Dee 2014.

${ }^{6}$ Loc. cit.

${ }^{7}$ Pierazzo, pers. comm.

${ }^{8}$ Cuben 1990: 4.

${ }^{9}$ Kirschner, Sweller \& Clark 2006: 76.

${ }^{10}$ Rehbein \& Fritze 2012: 62.

${ }^{11}$ Lindeman 1926.

12 Dewey 2008: 98.

13 Lindeman 1926: 6.

14 Merriam 2001.

15 Rehbein \& Fritze 2012: 73.

16 Knowles 1972; Adler 1952.

17 Snyder 2008: 2.

18 Thorne 2012.

19 Hansman 2001: 49.

${ }^{20}$ Mahony \& Pierazzo 2012: 224.

${ }^{21}$ Ruell 2013.

22 Scardamalia \& Bereiter 1989.

${ }^{23}$ Chickering \& Ehrmann 1996.

${ }^{24}$ University of Oxford (n.d.).

${ }^{25}$ Bauman \& Flanders (n.d.).

${ }^{26}$ Mandell 2013.

27 Chesley 2012.

${ }^{28}$ Burghart 2013.

${ }^{29}$ Text Encoding Initiative, n.d., 'Teach Yourself TEI.' 
30 Text Encoding Initiative, n.d., 'TEI Wiki'; Dee 2014.

${ }^{31}$ Van den Branden et al. 2010.

32 Terras 2011.

33 Vanhoutte 2011.

${ }^{34}$ Siemens \& Tittenberger 2009: 3.

${ }^{35}$ Crane et al. 2012.

36 Casanova 2004.

37 Kirschner, Sweller \& Clark 2006: 79.

38 Bodard 2010.

${ }^{39}$ Elliott et al. 2006-2016.

40 Bagnall 2010.

${ }^{41}$ Crane 2014: 4.

${ }^{42}$ Canonical Text Services at SourceForge [Online] <http://cite-architecture. github.io/> (last accessed October 2015).

${ }^{43}$ TAPAS Project: <http://tapasproject.org/>; TEICHI <http://www.teichi. org/>; CWRC-Writer <http://www.cwrc.ca/projects/infrastructure-projects/ technical-projects/cwrc-writer/>; TEI Boilerplate <http://dcl.ils.indiana.edu/ teibp/> (all links last accessed September 2014).

${ }^{44}$ Sublime: <http://www.sublimetext.com/>; Notepad++: <http://notepadplus-plus.org/>.

${ }^{45}$ Dee 2014.

\section{References}

Alpheios (n.d.). Retrieved from http://alpheios.net/content/alpheios-texts Bagnall, R. (2010). Integrating Digital Papyrology. In Online Humanities Scholarship: The Shape of Things to Come. Retrieved from https://archive. nyu.edu/handle/2451/29592

Bodard, G. (2010). EpiDoc: Epigraphic documents in XML for publication and interchange. In F. Feraudi-Gruénais (Ed.) Latin on Stone: Epigraphic Research and Electronic Archives. Lanham, MD: Lexington Books.

Brown University Women Writers Project (n.d.). Resources for Teaching and Learning Text Encoding. Journal of the Text Encoding Initiative. Retrieved from http://www.wwp.brown.edu/outreach/resources.html

Brown University (n.d.). TEI-L Home Page. Retrieved from http://listserv. brown.edu/archives/cgi-bin/wa?A0=TEI-L

Burghart, M. (2013). TEI Cheatsheets. TEI Wiki. Retrieved from http://wiki. tei-c.org/index.php/TEI_Cheatsheets

Casanova, P. (2004). The World Republic of Letters. Boston, USA: Harvard University Press.

Chesley, A. (2013). TEI: an overview. Retrieved from http://www.youtube.com/ watch?v=R6iiIFrWvmU 
Chickering, A.W. \& Ehrmann, S.C. (1996). Implementing the seven principles: Technology as a lever. Retrieved from http://www.tltgroup.org/programs/ seven.html

Crane, G. (2010). Give us editors! Re-inventing the edition and re-thinking the humanities. Connexions. Retrieved from http://cnx.org/content/m34316/ latest/

Crane, G. (2014). The Digital Loeb Classical Library - a view from Europe. Perseus Digital Library Updates: News and Announcements from the Perseus Digital Library. Retrieved from http://sites.tufts.edu/perseus updates/2014/09/22/the-digital-loeb-classical-library-a-view-fromeurope/

Crane, G., Almas, B., Babeu, A., Cerrato, L., Harrington, M., Bamman, D. \& Diakoff H. (2012). Student Researchers, Citizen Scholars and the Trillion Word Library. Retrieved from http://www.humanities.ufl.edu/pdf/ Crane-\%20Student\%20Researchers,\%20Citizen\%20Scholars,\%20and\%20 the\%20Trillion\%20Word\%20Library.pdf

Cuban, L. (1990). Reforming Again, Again, and Again. Educational Researcher 19(3-13).

Dee, S. (2014). Learning the TEI In a Digital Environment. Journal of the Text Encoding Initiative 7. Retrieved from http://jtei.revues.org/968

Dewey, J. (2008). Democracy and Education. Radford, VA: Wilder Publications.

Elliott, T., Bodard, G., Cayless, H. et al. (2006-2016). EpiDoc: Epigraphic Documents in TEI XML. Retrieved from http://epidoc.sf.net/

Hansman, C. A. (2001). Context-Based Adult Learning. In S.B. Merriam (Ed.), The new update on adult learning theory (pp. 43-113). New Directions for Adult and Continuing Education, No. 89. San Francisco: Jossey-Base.

Kirschner, P. A., Sweller, J. \& Clark, R. (2006). Why Minimal Guidance During Instruction Does Not Work: An Analysis of the Failure of Constructivist, Discovery, Problem-Based, Experiential, and Inquiry-Based Teaching. Educational Psychologist, 41(2): 75-86.

Knoll, M. (2011). Von Aristoteles zu Dewey. Zum Ursprung der Maxime "learning by doing”. Originalbeitrag. Überarbeitete Fassung von Dewey, Kilpatrick und "progressive" Erziehung. Kritische Studien zur Projektpädagogik. Bad Heilbrunn: Klinkhardt. pp. 287-298. Retrieved from http://www.mi-knoll. de/128401.html

Knowles, M. (1972). Innovations in Teaching Styles and Approaches Based Upon Adult Learning. Journal of Education for Social Work, 8(2): 32-39.

Lindemann, E. (1926). The Meaning of Adult Education. New York, NY: New Republic.

Mahony, S. \& Pierazzo, E. (2012). Teaching Skills or Teaching Methodology? In Hirsch, B.D. (2012) Digital Humanities Pedagogy. Open Book Publishers Retrieved from http://www.openbookpublishers.com 
Mandell, L. (2013). Introduction to Digital Textual Editing: An UNOFFICIAL Guide to the Value of TEI. Retrieved from http://www.slideshare.net/ mandellc/tei-and-xslt-23711832

Perseids (n.d.). Perseids Editing Environment. Retrieved from http://sosol. perseids.org/sosol/

Rehbein, M. \& Fritze, F. (2012). Hands-On Teaching Digital Humanities: A Didactic Analysis of a Summer School Course on Digital Editing. In B. D. Hirsch (Ed.), Digital Humanities Pedagogy. Open Book Publishers. Retrieved from http://www.openbookpublishers.com

Reuell, P. (2013). Online learning: It's different. HarvardScience: Science and Engineering at Harvard University. Retrieved from http://news.harvard. edu/gazette/story/2013/04/online-learning-its-different/

Siemens, G. \& Tittenberger, P. (2009). Handbook of Emerging Technologies for Learning. Retrieved from http://elearnspace.org/Articles/HETL.pdf

Snyder, I. (2008). Research Approaches to the Study of Literacy, Technology and Learning. In K. A. King \& N. H. Hornberger (Eds.), Encyclopedia of Language and Education, 2nd Edition, Volume 10: Research Methods in Language and Education: Kluwer 299-308. New York, NY: Springer Science+Business Media, LLC.

Terras, M. (2011). Birth of TEI by Example. Retrieved from http://melissaterras. blogspot.de/2011/11/birth-of-tei-by-example.html

Text Encoding Initiative Consortium (n.d.). Teach Yourself TEI. Retrieved from http://www.tei-c.org/Support/Learn/tutorials.xml

Text Encoding Initiative Consortium (n.d.). TEI Wiki. Retrieved from http:// wiki.tei-c.org/index.php/Main_Page

Thorne, S. L., Fischer, I. \& Lu, X. (2012). The semiotic ecology and linguistic complexity of an online game world. ReCALL, 24: 279-301.

Terras, M., Van den Branden, R. \& Vanhoutte, E. (2009). The need for TEI By Example. Literary and Linguistic Computing 24(3): 297-306.

University of Oxford (n.d.). Getting started using TEI. Retrieved from http://tei. oucs.ox.ac.uk/GettingStarted/html

Vanhoutte, E. (2011). So You Think You Can Edit? The Masterchef Edition. Retieved from http://edwardvanhoutte.blogspot.de/2011/10/so-you-thinkyou-can-edit-masterchef.html 